\title{
Simulation of a Plate Heat Exchanger Operating with Nanofluid Coolant Using CFD
}

Tiari R. Rezende*, Regina F. Vianna, Samuel Luporini

Postgraduate Program in Chemical Engineering, Federal University of Bahia, Salvador 40210-910, Brazil

Corresponding Author Email: tiarirezende@ hotmail.com

https://doi.org/10.18280/ijht.390126

Received: 22 May 2020

Accepted: 14 December 2020

\section{Keywords:}

$C F D$, heat transfer, nanofluid, plate heat exchanger, simulation

\begin{abstract}
The use of nanofluids as coolant fluid in a plate heat exchanger (PHE) was investigated by conducting 3D CFD (Computational Fluid Dynamics) simulations. $\mathrm{Al}_{2} \mathrm{O}_{3} /$ water nanofluid with volume concentrations of $2 \%, 3 \%$ and $4 \%$ was used as coolant fluid and water as hot fluid. In addition, the effects of corrugation angle of the plates were analyzed by varying them between $0^{\circ}$ and $60^{\circ}$. Validation was performed by using heat transfer coefficients experimentally obtained in a previous study. Results show that the use of nanofluids in higher concentrations improves the performance of the PHE's parameters. The angles of $30^{\circ}$ and $60^{\circ}$ between the plates reduce pressure drop and reflux regions improving the heat exchange. The variations of the nanofluid flow must take into account the proper pressure drop for the process where is PHE is employed because the increased flow rate results in a significant increase in the pressure drop. In general, this work has potential to be used for enhancing the design of PHEs.
\end{abstract}

\section{INTRODUCTION}

The optimization of heat transfer in industrial processes has become of great importance in the development of sustainable energy strategies. Therefore, the design of high-performance heat exchangers is of great interest for various industrial applications [1].

Plate heat exchangers (PHE) are widely employed due to their high performance and compactness. However, water and oil, which are usually used as coolant fluids, have relatively low thermal conductivity, which ends up limiting the thermal efficiency of these systems. One of the alternatives is using coolant nanofluids, which are a mixture of nanoparticles (usually metals and metal oxides) and the usual coolant. Previous works have shown that coolant nanofluid is able to dissipate more heat due to its greater thermal conductivity, which in turn results in the better thermal performance [2, 3].

Pourhoseini et al. [4] proposed a simple and inexpensive process for the synthesis of an $\mathrm{Ag} /$ water nanofluid and determined how the variations in the volumetric flow rate and nanofluid concentrations between 0 and $10 \mathrm{mg} / \mathrm{L}$ affected the thermal features of the nanofluid and the total heat transfer coefficient of a PHE. Results suggested that the global heat transfer coefficient increases with a combination of both nanofluid concentration and volumetric flow rate. However, the authors also showed that the volumetric flow rate has a major effect on this parameter since the curve for the concentration of nanoparticles with the thermal conductivity reaches a maximum at $2.5 \mathrm{mg} / \mathrm{L}$ of nanoparticle. This is due to the aggregation phenomenon and to the smaller area-volume ratio for high concentrations which provokes a decrease in the effective thermal conductivity.

The thermo-hydraulic performance of a PHE with a $\mathrm{MgO} /$ ethylene glycol nanofluid in different concentrations was investigated by Arya et al. [5]. Results revealed that the flow rate and concentration increase the convective heat transfer coefficient and consequently the thermo-hydraulic performance. Nevertheless, both also increased the system pressure drop

Elias et al. [6] conducted laboratory experiments to compare heat transfer and pressure drop in a PHE with chevron corrugations of $30^{\circ}$ and $60^{\circ}$ using nanofluid concentrations varying from 0 to $0.5 \%$ in volume. The $60^{\circ}$ angle presented a better performance than the $30^{\circ}$ angle. For the highest concentration, the global heat transfer coefficient and the heat transfer rate for this angle were $7.8 \%$ and $15.4 \%$ higher than for pure water, respectively.

Bhattad et al. [7] performed several experiments using hybrid nanofluids with different nanoparticle concentrations as coolant to assess the performance of a PHE. The authors observed an enhancement of up to $15.2 \%$ in the heat transfer coefficient with the use of nanofluids, with a negligible increase of $0.02 \%$ in pump work and a $2.96 \%$ increase in the performance of PHE.

Technological advances have made possible the use of Computational Fluid Dynamics (CFD) for the study of many complex systems, including plate heat exchangers. By means of CFD, Khoshvaght-Aliabadi et al. [8] studied the heat transfer coefficient and flow features of a $\mathrm{Cu} /$ water nanofluid in a PHE. Their simulations provided results based on singlephase models and two two-phase models (mixture and Eulerian). The mixture model predicted more reliable results when compared to the homogeneous and Eulerian approaches. The mean relative errors between the experimental data and the CFD simulation results based on the single-phase model varied from 12 to $16 \%$, whereas for the mixture and the Eulerian models they varied between $1.5-4 \%$ and $6-8 \%$, respectively.

Tiwari et al. [9] conducted numerical simulations of heat transfer and fluid flow rate in a PHE with nanofluids by considering homogeneous mixtures and using CFD. Validation against experimental data suggested that the 
homogeneous model was able to predict the performance of the PHE with fair accuracy.

A numerical and experimental study on the efficacy of a nanofluid in a miniaturized PHE with modular surface was carried out by Stogiannis et al. [10]. A validated CFD code was employed to visualize the velocity field and predict the pressure drop. The results revealed that, for a given operating temperature, less coolant and, as a result, less pumping energy was needed when the nanofluid replaced pure water. The use of nanofluid has proved to be an attractive solution for small devices or low-power applications.

Bhattad et al. [11] conducted CFD and experimental investigations in a PHE using hybrid nanofluid $\left(\mathrm{Al}_{2} \mathrm{O}_{3}+\right.$ $\mathrm{MWCNT}$ /water) in different concentrations to assess how the heat transfer and pressure drop were affected. A discrete-phase model was used and compared with experimental data and homogeneous model. The discrete-phase model provided a better result than the homogeneous model for the analysed system. Nonetheless, the homogeneous model was more accurate for representing the non-hybrid nanofluid.

In the same direction, Javadi et al. [12] and Tiwari et al. [13] showed that the use of some nanofluids in this type of heat exchangers can enhance the thermal performance. On the other hand, Kabeel et al. [14] concluded that the increase in the concentration of nanofluids in PHEs does not always promote a substantial increase in the heat transfer coefficient and in the transmitted power. Due to the existing discrepancies in the findings, this work considered important to conduct further investigations in the area [15].

Therefore, this work aimed at studying, by means of computational fluid dynamics, a plate heat exchanger operating with an $\mathrm{Al}_{2} \mathrm{O}_{3}$ /water nanofluid as coolant fluid based on the experimental study of Pandey and Nema [16], by varying parameters such as concentration and nanofluid flow. Therefore, the use of nanofluids is considered to improve the PHE performance.

\section{METHODOLOGY}

\subsection{Geometry}

The geometric design is the first step of the CFD preprocessing and intends to represent both the domain of the fluid and the solid structure involving it. The geometry was designed based on Pandey and Nema [16], which is also the source of other parameters used in the simulation and experimental data employed for model validation. The software ANSYS SpaceClaim was used to create the 3D geometry shown in Figure 1. The PHE plates were in structural steel and a surface area of $0.032 \mathrm{~m}^{2}$.

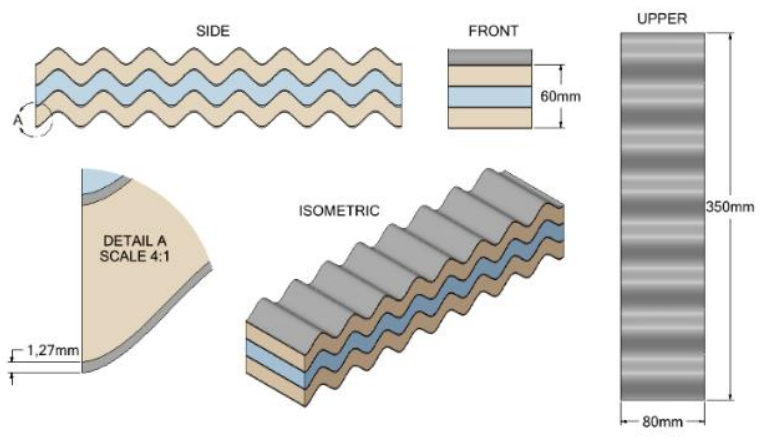

Figure 1. PHE geometry and dimensions
Following an hexahedral mesh was created and refined. The mean velocity of the nanofluid at the heat exchanger's outlet was used as the mesh convergence parameter. The mesh was considered fine enough for residual errors of around $10^{-4}$ and when the physical stabilization was achieved. An even more refined mesh was generated for representing the plates and a Boundary Layer was used to represent the contact between the fluid and the plate. Figure 2 shows the geometry with the hexahedral mesh formed by approximately 400 thousand elements. The skewness of the mesh, which represents the deviation of the vector that connects the center of the neighbor volumes to the center of the face, was approximately 0.35 , and the maximum value below 0.90 , which made the mesh very suitable for the CFD study.

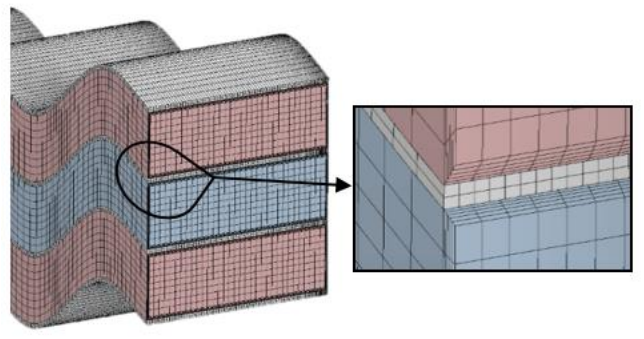

Figure 2. PHE geometry and the generated mesh

To assess how the corrugation angle influences, the behavior of the nanofluid and the heat exchange performance, new fluid domains were created as shown in Figure 3, for plate corrugation angles of $30^{\circ}$ and $60^{\circ}$ with respect to the direction of the nanofluid flow.

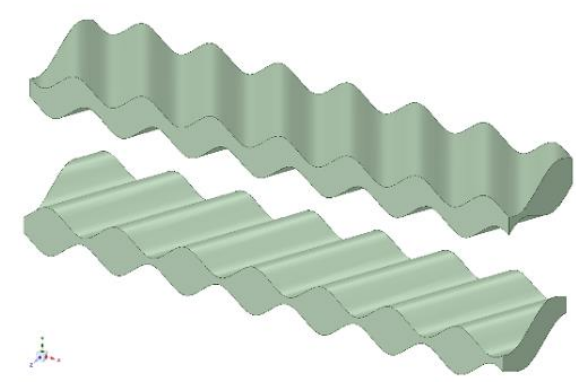

Figure 3. Fluid simulation domain with plate angles of $30^{\circ}$ (top) and $60^{\circ}$ (bottom)

\subsection{Boundary conditions}

Simulations were carried out by considering four different coolant flow rates: $2 \mathrm{lpm}, 3 \mathrm{lpm}, 4 \mathrm{lpm}$ and $5 \mathrm{lpm}$ and a hot fluid (water) flow rate of $2 \mathrm{lpm}$ in countercurrent. Coolant and hot fluid inlet temperatures were $300.20 \mathrm{~K}$ and $311.50 \mathrm{~K}$, respectively. Heat losses to the vicinity were considered negligible.

Fluids were considered incompressible and homogeneous, their thermophysical properties were assumed constant as shown in Table 1 and there were no phase changes inside the PHE. The thermal dynamics of the metal plates was considered insignificant. Each simulation was performed for pure water and $\mathrm{Al}_{2} \mathrm{O}_{3}$ nanocoolant concentrations of $2 \%, 3 \%$ and $4 \%$ vol. The homogeneous model was employed to represent the nanofluid, In summary, it were sixteen studies for each PHE geometry. 
Table 1. Thermophysical properties of nanofluids in different concentrations at $27^{\circ} \mathrm{C}[16]$

\begin{tabular}{lcccc}
\hline Fluid & $\begin{array}{c}\text { Thermal } \\
\text { conductivity } \\
(\mathbf{W} / \mathbf{m} \mathbf{~ K})\end{array}$ & $\begin{array}{c}\text { Density } \\
\left(\mathbf{k g} / \mathbf{m}^{\mathbf{3}}\right)\end{array}$ & $\begin{array}{c}\text { Specific } \\
\text { heat }(\mathbf{J} / \mathbf{k g} \\
\mathbf{K})\end{array}$ & $\begin{array}{c}\text { Viscosity } \\
(\mathbf{m P a})\end{array}$ \\
\hline$* \mathbf{2} \%$ & 0.625 & 1005 & 4039 & 2.200 \\
$* \mathbf{3} \%$ & 0.643 & 1050 & 3910 & 2.900 \\
$* \mathbf{4} \%$ & 0.662 & 1110 & 3430 & 7.500 \\
\hline$*$ Percentage of $\mathrm{Al}_{2} \mathrm{O}_{3}$ nanoparticles in a water volume &
\end{tabular}

\subsection{Governing equations}

Fluid dynamics problems with turbulent flow are described by the RANS (Reynolds Averaged Navier-Stokes) Eq. (1) and (2) which are a combination and adaptation of the fundamental fluid mechanics equations [17]:

$$
\begin{gathered}
\frac{\partial \rho}{\partial t}+\frac{\partial}{\partial x_{i}}\left(\rho u_{i}\right)=0 \\
\frac{\partial}{\partial t}\left(\rho u_{i}\right)+\frac{\partial}{\partial x_{j}}\left(\rho u, u_{j}\right)=-\frac{\partial p}{\partial x_{i}}+ \\
\frac{\partial}{\partial x_{j}}\left[\mu\left(\frac{\partial u_{i}}{\partial x_{j}}+\frac{\partial u_{j}}{\partial x_{i}}-\frac{2}{3} \delta_{i j} \frac{\partial u_{l}}{\partial x_{l}}\right)\right]+\frac{\partial}{\partial x_{j}}\left(-\rho \overline{u_{l}^{\prime} u_{j}^{\prime}}\right)
\end{gathered}
$$

These have the same general form of the Navier-Stokes equations, with the velocities and other variables of the solution now representing the mean values of the set. Although, in RANS equations, there are additional terms that represent the effects of the turbulence, such as the Reynolds stress, represented by $\left(-\rho \overline{u_{l}^{\prime} u_{j}^{\prime}}\right)$.

The standard $\kappa-\varepsilon$ turbulence model is used to model the turbulent flow. It incorporates two variables of the transport equation: the turbulent kinetic energy $(\kappa)$, and the energy dissipation rate $(\varepsilon)$, determining the turbulence on any scale of time or space [17].

The variables $\kappa$ and $\varepsilon$ are obtained through the transport Eq. (3) and (4).

$$
\begin{aligned}
& \frac{\partial}{\partial t}(\rho \kappa)+\frac{\partial}{\partial x_{i}}\left(\rho \kappa u_{i}\right)=\frac{\partial}{\partial x_{j}}\left[\left(\mu+\frac{\mu_{t}}{\sigma_{\kappa}}\right) \frac{\partial \kappa}{\partial x_{j}}\right]+ \\
& G_{\kappa}+G_{b}-\rho \varepsilon+S_{\kappa} \\
& \frac{\partial}{\partial t}(\rho \varepsilon)+\frac{\partial}{\partial x_{i}}\left(\rho \varepsilon u_{i}\right)=\frac{\partial}{\partial x_{j}}\left[\left(\mu+\frac{\mu_{t}}{\sigma_{\varepsilon}}\right) \frac{\partial \varepsilon}{\partial x_{j}}\right]+ \\
& C_{1 \varepsilon} \frac{\varepsilon}{\kappa}\left(G_{\kappa}+C_{3 \varepsilon} G_{b}\right)-C_{2 \varepsilon} \rho \frac{\varepsilon^{2}}{\kappa}+S_{\varepsilon}
\end{aligned}
$$

where, $C_{1 \varepsilon}$ and $C_{2 \varepsilon}$ are constants of the model whose values are 1.44 and 1.92 respectively. The turbulent Prandtl numbers for $\kappa$ and $\varepsilon$ are $\sigma_{\kappa}$ and $\sigma_{\varepsilon}$, also constant and with values 1.0 and 1.3, respectively. $S_{\kappa}$ and $S_{\varepsilon}$ are user-defined source terms. $G_{\kappa}$ is the generation of turbulent kinetic energy by the mean velocity gradients, which can be given by Eq. (5).

$$
G_{\kappa}=-\rho \overline{u_{i}^{\prime} u_{j}^{\prime}} \frac{\partial u_{j}}{\partial x_{i}}
$$

In Eq. (3) and Eq. (4), $G_{b}$ represents the generation of turbulent kinetic energy due to the fluctuability and can be defined as:

$$
G_{b}=\beta g_{i} \frac{\mu_{t}}{\operatorname{Pr}_{t}} \frac{\partial T}{\partial x_{i}}
$$

where, $\operatorname{Pr}_{t}$ is the turbulent Prandtl number, whose standard value is 0.85 , and $\beta$ is the thermal expansion coefficient, given by:

$$
\beta=\frac{1}{\rho}\left(\frac{\partial \rho}{\partial T}\right)_{p}
$$

The turbulent viscosity, $\mu_{\mathrm{t}}$, is calculated based on $\kappa$ and $\varepsilon$ as follows:

$$
\mu_{t}=\rho C_{\mu} \frac{\kappa^{2}}{\varepsilon}
$$

where, $\mathrm{C}_{\mu}$ has the constant value of 0.09 [17].

The turbulent heat transport is modeled using the Reynolds analogy concept for the turbulent momentum transfer. The energy equation is given by:

$$
\begin{aligned}
& \frac{\partial}{\partial t}(\rho E)+\frac{\partial}{\partial x_{i}}\left[u_{i}(\rho E+p)\right]= \\
& \frac{\partial}{\partial x_{j}}\left(k_{e f f} \frac{\partial T}{\partial x_{j}}+u_{i}\left(\tau_{i j}\right)_{e f f}\right)+S_{h}
\end{aligned}
$$

where, $E$ is the total energy and $k_{\text {eff }}$ is the effective thermal conductivity, which, for the standard $\kappa-\varepsilon$ turbulence model, is given by:

$$
k_{e f f}=k+\frac{c_{p} \mu_{t}}{P r_{t}}
$$

Eq. (11) describes energy transportation through heat exchanger's plates.

$$
\frac{\partial}{\partial t}(\rho h)+\nabla \cdot(\vec{v} \rho h)=\nabla \cdot(k \nabla T)+S_{h}
$$

where, $k$ is the thermal conductivity [17].

\section{RESULTS AND DISCUSSION}

\subsection{Validation}

Heat transfer coefficients for each nanofluid concentration and flow rates are shown in Figure 4. In comparison to the experimental results published by Pandey and Nema [16], the mean relative error was of $9.67 \%$. The main source of this error may be due to the use of single-phase model used for the nanofluids. 


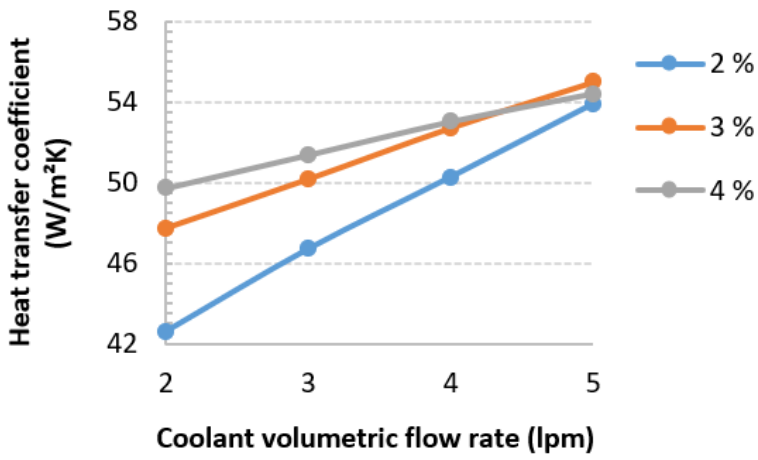

Figure 4. Variation of heat transfer coefficient for the coolants with flow rate

\subsection{PHE study}

Temperature profiles along the coolant domain of the PHE were assessed and greater temperature variations were observed for the highest nanofluid concentration, as shown in Figure 5. However, it could be observed that there are regions close to the plates where high temperature values occur for the smallest nanofluid concentrations. This can be explained by the presence of regions with formation of vortices that keep part of fluid for a longer time performing the thermal exchange and raising its temperature. Figure 6 shows flow streamlines for the different nanofluids concentrations and by keeping the same fluid flow rate. It can be seen that for smaller nanofluid concentrations there were formation of vortices in the flow channels of the plate, which explains the increase in the temperature of these regions.

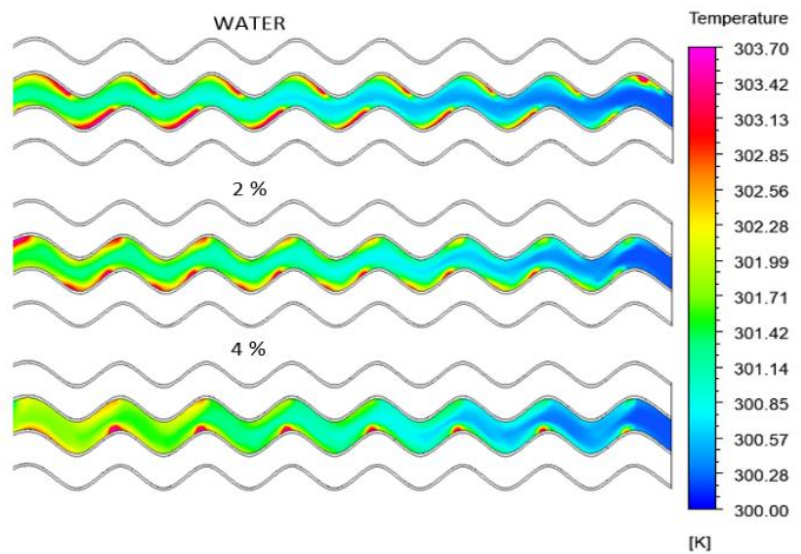

Figure 5. Temperature profile of water and nanofluid (2\% and $4 \%$ nanoparticles vol.) flow

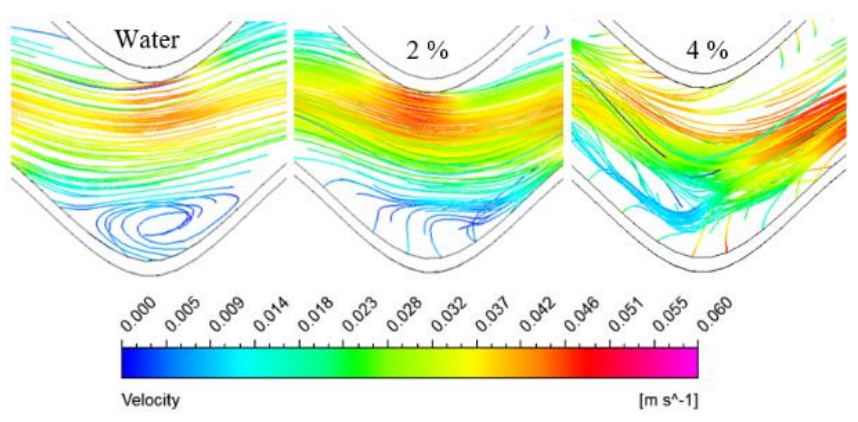

Figure 6. Water and of nanofluid (2\% and $4 \%$ vol.) flow streamlines

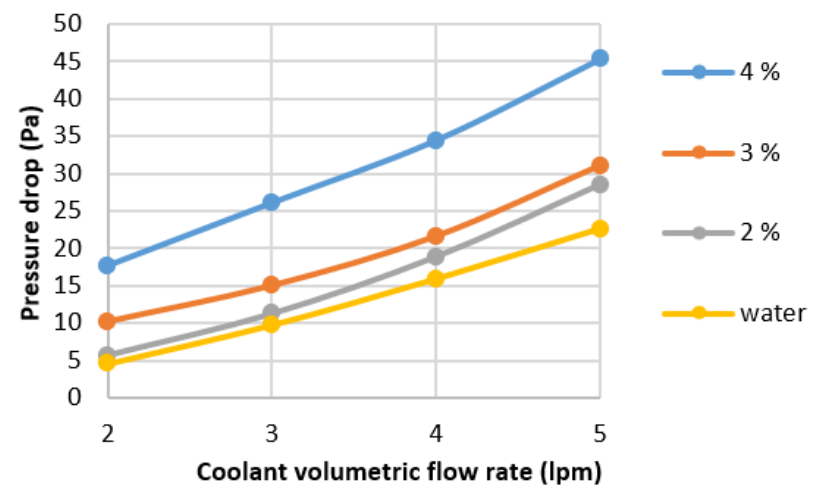

Figure 7. Variation of pressure drop of the coolants with coolant flow rate

The variation of the pressure drop with the volume flow rate for the various concentrations is shown in Figure 7 for a hot water flow rate of $2 \mathrm{lpm}$ in the adjacent channels. It can be seen that the pressure drop increases with both the nanofluid flowrate and concentration. This can be explained by the increase of the nanofluid viscosity with its concentration as shown in Table 1. Since pressure drop is a function of fluids density, flow rate and viscosity, it explains the increase in the pressure drop for higher nanofluid concentrations.

By using a linear regression, it is possible to determine that an increase of about $20 \%$ in the nanofluid flow rate promotes a gain of approximately $30 \%$ in the pressure drop in the channel. So, one of the important criteria to be observed in the determination of the operating flow rate is the maximum value of the pressure drop allowed for the system as a whole where the PHE is to be implemented.

The heat flow profile for the system was obtained and is shown in Figure 8 for different nanofluid concentrations with the flow rate of $2 \mathrm{lpm}$. An increase in the heat flow rate was observed when the concentration of the nanofluid grew, which matches with the obtained temperature profiles. The mean values of the heat flow rates in the plate were $2745.94 \mathrm{~W} / \mathrm{m}^{2}$ $2980.72 \mathrm{~W} / \mathrm{m}^{2}$ and $3172.68 \mathrm{~W} / \mathrm{m}^{2}$ for nanofluids concentrations of $2 \%, 3 \%$ and $4 \%$ vol. vol., respectively.

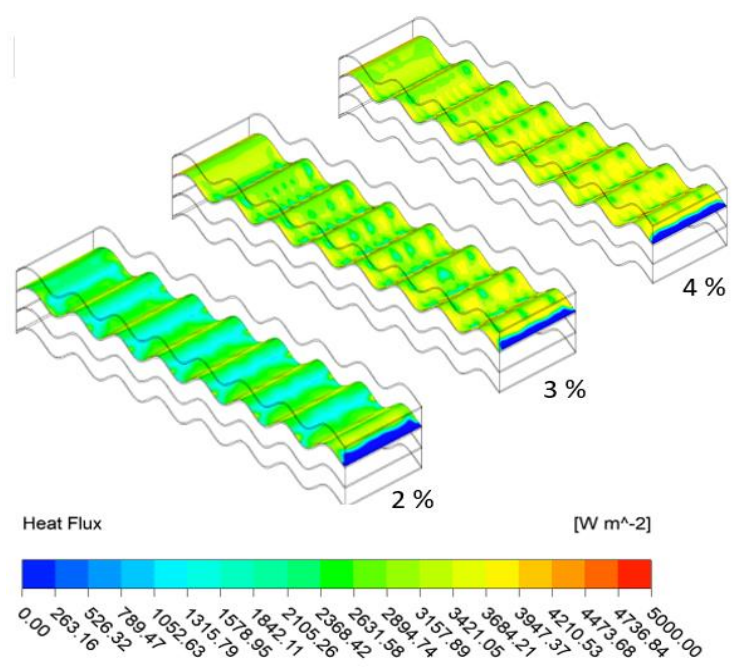

Figure 8. Heat flow profile on the internal plate of the PHE for 2,3 and $4 \%$ nanofluid concentrations

In summary, results show that the addition of nanoparticles has the ability to increase the convective heat transfer coefficient of the nanofluid for lower flow rates. Although, for 
higher flow rates, the increase in the rate of the heat transfer coefficient is practically irrelevant as shown in Figure 4 for the flow rate of $5 \mathrm{lpm}$.

Typically, the convective heat transfer coefficient increases with the intensity of the turbulence. This is due to the more turbulent flow, which has a thinner film fluid layer stagnating on the surface of heat transfer.

It is expected that Nusselt number follows the same behaviour of the heat transfer coeficcient shown in Figure 4. Both Nusselt and Reynolds numbers shall be calculated in future work.

\subsection{Geometry study}

Table 2 shows the pressure drop for the nanofluid side, the mean outlet temperature and the heat flow on the surface of the plate for the different geometries of the PHE by considering $2 \%$ vol. of $\mathrm{Al}_{2} \mathrm{O}_{3}$ and flow rate of $2 \mathrm{lpm}$. The angle is the slant of the top and bottom plates with respect to the flow direction.

Table 2. Results for different corrugation angles

\begin{tabular}{cccc}
\hline Angle & $\mathbf{0}^{\circ}$ & $\mathbf{3 0}^{\circ}$ & $\mathbf{6 0}^{\circ}$ \\
\hline Temperature $(\mathrm{K})$ & 302.03 & 302.73 & 302.71 \\
Pressure drop $(\mathrm{Pa})$ & 7.29 & 6.73 & 5.36 \\
Surface heat flux $\left(\mathrm{W} / \mathrm{m}^{2}\right)$ & 3588.1 & 4318.5 & 4193.0 \\
\hline
\end{tabular}

The angle of $30^{\circ}$ reached the highest temperature value, but without a significant difference from the angle of $60^{\circ}$, which, in turn, has the smallest value for the pressure drop, being significantly different from the other angles. Agreeing with the temperature, the angle of $30^{\circ}$ enabled a greater heat flow.

The velocity profiles in Figure 9 shows that when there is no angle between the plates, there is a greater formation of reflux regions than with angles of $30^{\circ}$ and $60^{\circ}$. Figure 10 also reveals that the angles allow a longer retention of the fluid in the PHE. The streamlines show the tortuous path run by the fluid to the channel's outlet.

\section{CONCLUSIONS}

The present work successfully employs CFD simulations for the analysis of nanofluids in plate heat exchangers. The obtained homogeneous model represented the experimental data of Pandey and Nema [16] with accuracy greater than $90 \%$.

The thermal exchange was enhanced by the increase in the $\mathrm{Al}_{2} \mathrm{O}_{3}$ nanoparticles concentration up to $4 \%$ vol. in the coolant fluid, which was observed by means of the mean temperature at the heat exchanger's outlet, as well as by the increase in the heat transfer coefficient and the increase in the heat flow rate. However, it shall be stressed that the increase in the nanofluid concentration also magnified the pressure drop it was also observed that an increase of about $20 \%$ in the nanofluid flow rate caused a $30 \%$ increase in the pressure drop.

Corrugation angles of $30^{\circ}$ and $60^{\circ}$ improves the performance of the PHE working with nanofluids as observed in previous studies with conventional coolants.

Therefore, the use of nanofluid can be considered relevant to enhance the general performance of a PHE, but other parameters must be taken into account, such as costs, pressure drop and corrosive effects that the nanofluid might add to the process, which can represent future study subjects.
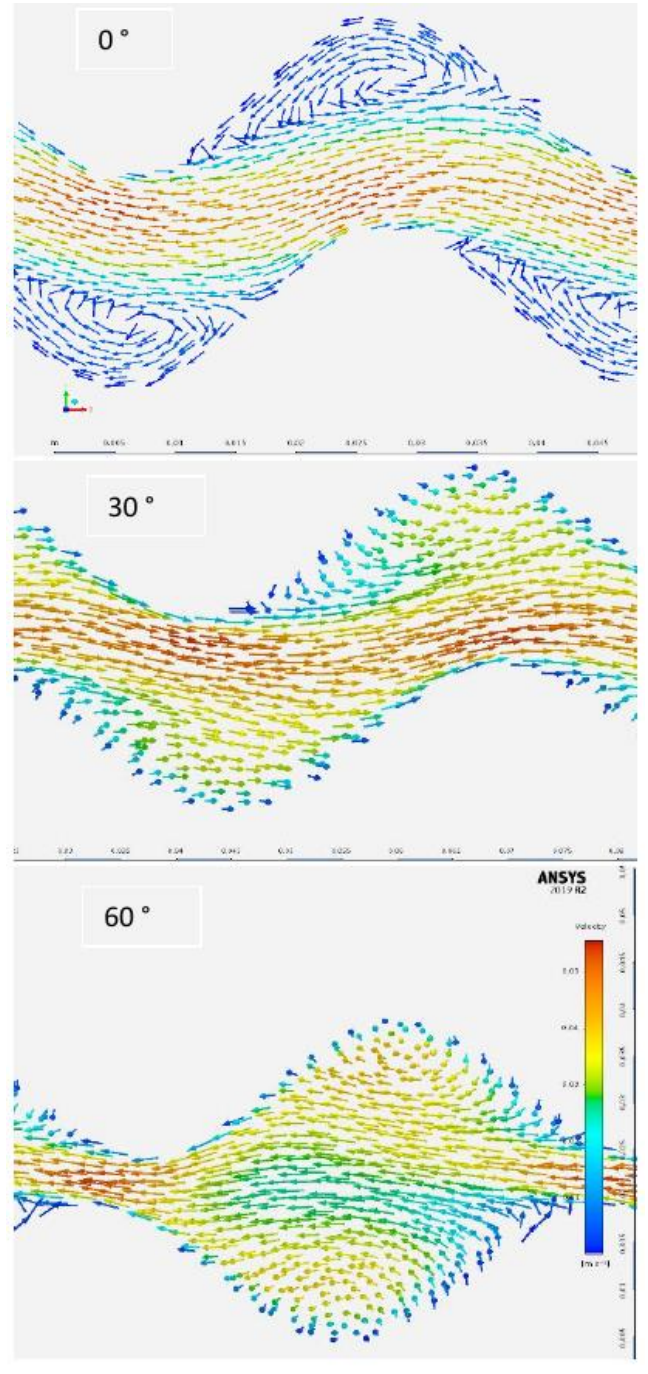

Figure 9. Velocity profile of the nanofluid flow in the geometry without angle, with $30^{\circ}$, and $60^{\circ}$

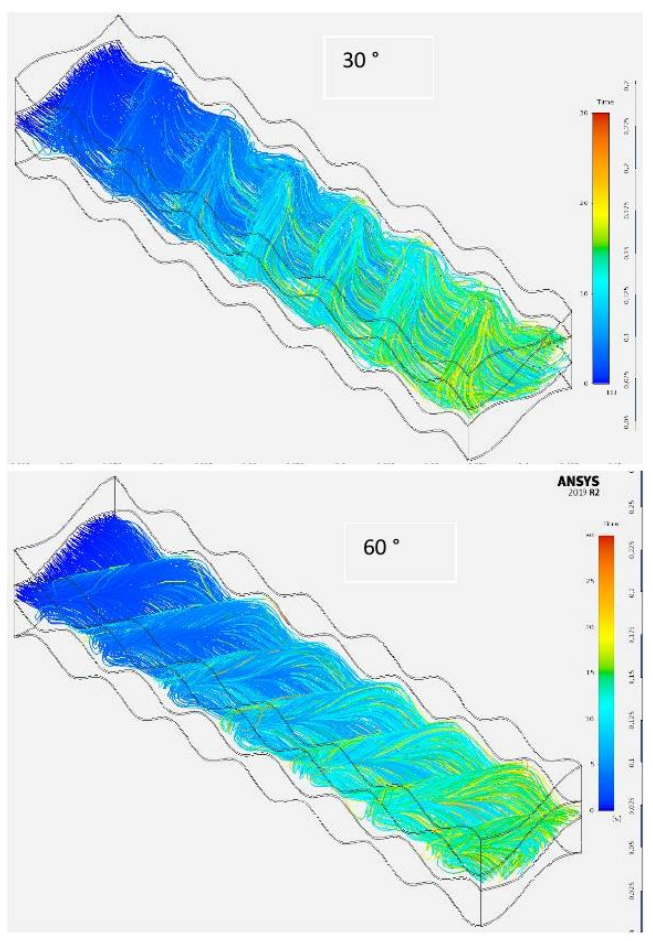

Figure 10. Nanofluid flow streamlines for the geometries with $30^{\circ}$ and $60^{\circ}$ 


\section{ACKNOWLEDGMENT}

This work was supported by the Foundation for Research Support of the State of Bahia (Approval/contract BOL0353/2019).

\section{REFERENCES}

[1] Xu, K., Smith, R. (2018). Design and optimization of plate heat exchanger networks. Elsevier Masson SAS, 44: 451-456. https://doi.org/10.1016/B978-0-444-642417.50070-7

[2] Babita, Sharma, S.K., Gupta, S.M. (2016). Preparation and evaluation of stable nanofluids for heat transfer application: A review. Experimental Thermal and Fluid Science, 79: 202-212. https://doi.org/10.1016/j.expthermflusci.2016.06.029

[3] Sajid, M.U., Ali, H.M. (2018). Thermal conductivity of hybrid nanofluids: A critical review. International Journal of Heat and Mass Transfer, Elsevier Ltd, 126: 211-234.

https://doi.org/10.1016/j.ijheatmasstransfer.2018.05.02

[4] Pourhoseini, S., Naghizadeh, N., Hoseinzadeh, H. (2018). Effect of silver-water nanofluid on heat transfer performance of a plate heat exchanger: An experimental and theoretical study. Powder Technology, Elsevier, 332: 279-286. https://doi.org/10.1016/j.powtec.2018.03.058

[5] Arya, H., Sarafraz, M.M., Arjomandi, M. (2018). Heat transfer and fluid flow of $\mathrm{MgO} /$ ethylene glycol in a corrugated heat exchanger. Journal of Mechanical Science and Technology, 32(8): 3975-3982. https://doi.org/10.1007/s12206-018-0748-x

[6] Elias, M.M., Saidur, R., Ben-Mansour, R., Hepbasli, A., Rahim, N.A., Jesbains, K. (2018). Heat transfer and pressure drop characteristics of a plate heat exchanger using water based $\mathrm{Al}_{2} \mathrm{O}_{3}$ nanofluid for $30^{\circ}$ and $60^{\circ}$ chevron angles. Heat and Mass Transfer, 54: 2907-2916. https://doi.org/10.1007/s00231-018-2335-1

[7] Bhattad, A., Sarkar, J., Ghosh, P. (2019). Experimentation on effect of particle ratio on hydrothermal performance of plate heat exchanger using hybrid nanofluid. Applied Thermal Engineering, 162. https://doi.org/10.1016/j.applthermaleng.2019.114309

[8] Khoshvaght-Aliabadi, M., Hormozi, F., Zamzamian, A. (2014). Effects of geometrical parameters on performance of plate-fin heat exchanger: Vortexgenerator as core surface and nanofluid as working media. Applied Thermal Engineering, Elsevier Ltd, 70(1): 565579.

https://doi.org/10.1016/j.applthermaleng.2014.04.026

[9] Tiwari, A.K., Ghosh, P., Sarkar, J., Dahiya, H., Parekh, J. (2014). Numerical investigation of heat transfer and fluid flow in plate heat exchanger using nanofluids. International Journal of Thermal Sciences, Elsevier Masson SAS, 85: 93-103. https://doi.org/10.1016/j.ijthermalsci.2014.06.015

[10] Stogiannis, I.A., Mouza, A.A., Paras, S.V. (2015). Efficacy of $\mathrm{SiO}_{2}$ nanofluids in a miniature plate heat exchanger with undulated surface. International Journal of Thermal Sciences, 92: 230-238. https://doi.org/10.1016/j.ijthermalsci.2015.01.035

[11] Bhattad, A., Sarkar, J., Ghosh, P. (2018). Discrete phase numerical model and experimental study of hybrid nanofluid heat transfer and pressure drop in plate heat

exchanger. International Communications in Heat and Mass Transfer, Elsevier, 91: 262-273. https://doi.org/10.1016/j.icheatmasstransfer.2017.12.02

[12] Javadi, F.S., Sadeghipour, S., Saidur, R., Boroumandjazi, G., Rahmati, B., Elias, M.M., Sohel, M.R. (2013). The effects of nanofluid on thermophysical properties and heat transfer characteristics of a plate heat exchanger. International Communications in Heat and Mass Transfer, Elsevier Ltd, 44: 58-63. http://dx.doi.org/10.1016/j.icheatmasstransfer.2013.03.0 17

[13] Tiwari, A.K., Ghosh, P., Sarkar, J. (2013). Heat transfer and pressure drop characteristics of $\mathrm{CeO}_{2} /$ water nanofluid in plate heat exchanger. Applied Thermal Engineering, Elsevier Ltd, 57(1-2): 24-32. https://doi.org/10.1016/j.applthermaleng.2013.03.047

[14] Kabeel, A.E., Abou El Maaty, T., El Samadony, Y. (2013). The effect of using nanoparticles on corrugated plate heat exchanger performance. Applied Thermal Engineering, Elsevier Ltd, 52(1): 221-229. https://doi.org/10.1016/j.applthermaleng.2012.11.027

[15] Bahiraei, M., Rahmani, R., Yaghoobi, A., Khodabandeh, E., Mashayekhi, R., Amani, M. (2018). Recent research contributions concerning use of nanofluids in heat exchangers: A critical review. Applied Thermal Engineering, 133: 137-159. https://doi.org/10.1016/j.applthermaleng.2018.01.041

[16] Pandey, S.D., Nema, V.K. (2012). Experimental analysis of heat transfer and friction factor of nanofluid as a coolant in a corrugated plate heat exchanger. Experimental Thermal and Fluid Science, 38: 248-256. https://doi.org/10.1016/j.expthermflusci.2011.12.013

[17] ANSYS- Fluent User's Guide. (2013). ANSYS Fluent Theory Guide. Release, 15.0.

\section{NOMENCLATURE}

$\begin{array}{ll}C F D & \text { Computational fluid dynamics } \\ C_{1 \varepsilon}, C_{2 \varepsilon} e C_{\mu} & \text { constants of the turbulence model, dimensionless } \\ c_{p} & \text { specific heat, } \mathrm{J} . \mathrm{kg}^{-1} \cdot \mathrm{K}^{-1} \\ E & \text { total energy, } \mathrm{J} \\ g & \text { gravitational acceleration, } \mathrm{m} . \mathrm{s}^{-2} \\ G & \text { turbulent kinetic energy generation, } \mathrm{J} \\ h & \text { sensitive enthalpy, } \mathrm{J} \cdot \mathrm{kg}^{-1} \cdot \mathrm{K}^{-1} \\ k & \text { thermal conductivity, W.m- } \mathrm{K}^{-1} \\ k_{e f f} & \text { effective termal conductivity, W. } \mathrm{m}^{-1} . \mathrm{K}^{-1} \\ p & \text { pressure, Pa } \\ P H E & \text { Plate heat exchanger } \\ P r & \text { Prandtl number, dimensionless } \\ P r_{t} & \text { turbulent Prandtl number, dimensionless } \\ R A N S & \text { Reynolds Averaged Navier-Stokes } \\ S_{h} & \text { volumetric heat source, J } \\ T & \text { temperature, } \mathrm{K} \\ t & \text { time, s } \\ v & \text { velocity, m.s }\end{array}$

\section{Greek symbols}

$\begin{array}{ll}\beta & \text { thermal expansion coefficient, } \mathrm{K}^{-1} \\ \mu & \text { dynamic viscosity, } \mathrm{kg} \cdot \mathrm{m}^{-1} \cdot \mathrm{s}^{-1} \\ \mu_{t} & \text { turbulent viscosity, } \mathrm{kg} \cdot \mathrm{m}^{-1} \cdot \mathrm{s}^{-1} \\ \delta & \text { delta function, units vary } \\ \rho & \text { density, } \mathrm{kg} . \mathrm{m}^{-3} \\ \sigma_{\varepsilon} \text { e } \sigma_{\kappa} & \text { turbulent Prandtl numbers, dimensionless } \\ \tau & \text { shear stress, Pa }\end{array}$

